\title{
Catfish Noodling Forearm Injury Requiring Urgent Surgical Treatment: A Case Report and Review of the Literature
}

\author{
Courtney R.J. Kaar, BS; Christina Plikaitis, MD; Kevin W. Germino, MD; Albert K. Nakanishi, MD, MPH \\ From the Saint Louis University Medical School, St. Louis, MO (Ms Kaar); the Department of Plastic and Reconstructive Surgery, Saint Louis \\ University, St. Louis, MO (Dr Plikaitis); and the Department of Pediatrics, Division of Emergency Medicine, Saint Louis University, St. Louis, MO \\ (Drs Germino and Nakanishi).
}

\begin{abstract}
"Noodling" is an ancient form of hand fishing recently gaining in popularity as a hobby and sport. We present one of the first case reports of a noodling injury in an adolescent male seeking to land a large catfish, and also review the literature on catfish-related injuries.
\end{abstract}

Key words: noodling, hand fishing, catfish injury, fishing injury, tendon laceration

\section{Introduction}

Catfish noodling has become a popular and adventurous recreational activity in many parts of the United States. The practice involves catching fish and turtles often in blind underwater enclosures with only the fisherman's hands. Noodler explore muddy or rocky holes feeling for fish and entice them to bite their hands while exploring a fish's nest. Upon being bitten, the noodler will grab the fish and pull it out of the hole by its jaw. ${ }^{1}$ Noodling can be considered more challenging and provide a personal interaction with nature as opposed to traditional fishing with a rod and reel. ${ }^{1}$ There have been some case reports of puncture wounds from catfish spines and aquatic infection due to catfish injuries, although only a few of these have been specified to have occurred while noodling. ${ }^{2-19}$ We present the case of a 14-year-old patient who sustained hand abrasions and a dorsal forearm injury while catfish noodling that required urgent antibiotic administration and extensor tendon repair.

\section{Case Presentation}

A 14-year-old, right-hand dominant, otherwise healthy boy was transferred to our institution's emergency department for a right forearm injury sustained earlier in the day. The injury occurred in May. He had been noodling for

Corresponding author: Albert K. Nakanishi, MD, MPH, 1465 South Grand Boulevard, St. Louis, MO 63104 (e-mail: nakanimk@slu.edu). catfish with his bare hands. A catfish caused abrasions to the dorsal surface of his right hand before escaping. He also sustained a deep laceration to the extensor surface of his right forearm from a submerged rusty barrel in which the catfish was located. He presented with difficulty in moving his right hand and wrist.

On presentation he was afebrile with normal vital signs ( $97.4^{\circ} \mathrm{F}$, pulse 74 beats/min, respiratory rate 18 breaths/ min, and $\mathrm{O}_{2}$ saturation 98\%). Focused examination of his injured right upper extremity noted superficial abrasions to the dorsum of his hand and fingers (Figure 1). There was also a deep laceration $12 \mathrm{~cm}$ long on the extensor surface of the mid right forearm (Figure 2). The laceration was deep to fascia and transected the extensor musculature and some tendons. There was no active bleeding, and his hand was perfused distally. Distally ulnar, median, and radial sensation was intact to light touch. The patient had intact thumb motion. He was able to actively flex his other fingers and his wrist although that was limited secondary to guarding. He was unable to extend his fingers or wrist. The forearm, wrist, and hand radiographs demonstrated evidence of soft tissue injury only, without visible foreign bodies (Figures 3 and 4).

Owing to the nature of the patient's injuries, the plastic surgery service was consulted. He was started on cefazolin in the emergency department, given a tetanus booster, and a wound exploration; incision and drainage and extensor repair were planned for that evening. In the operating room, the tendons of the extensor carpi ulnaris, extensor digiti minimi, and extensor digitorum communis 


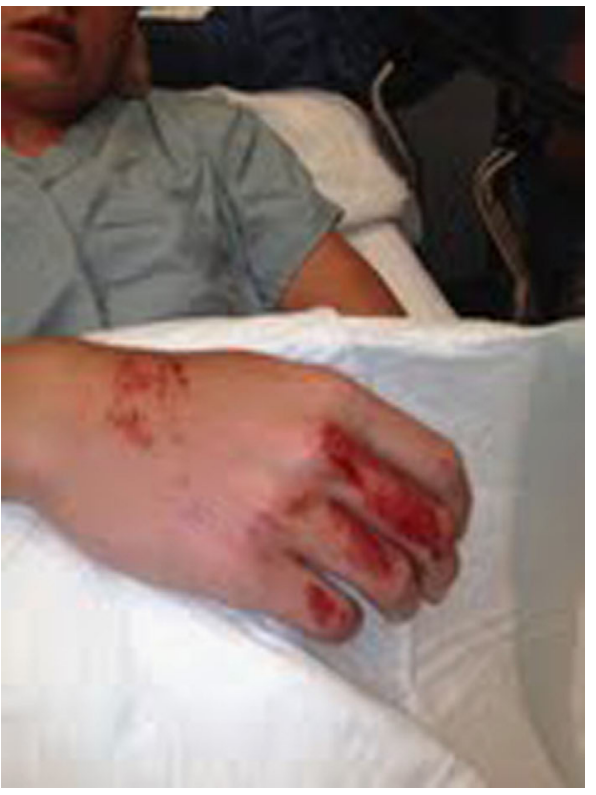

Figure 1. Clinical photographs: abrasions to the dorsum of the hand and fingers.

to the small finger were repaired, along with the muscle bellies of the extensor digitorum communis to the index, middle, and ring finger, extensor indicis proprius, and the abductor pollicis longus. He was given IV cefazolin, metronidazole, and piperacillin-tazobactam postoperatively.

The boy was discharged home in a splint the next day on a 2-week course of oral amoxicillin-clavulanate and a 3 -week course of oral metronidazole. He began occupational therapy the second postoperative week and was maintained in a splint for 6 weeks. He was doing well at his 2-month postoperative visit although he had yet to regain full wrist motion or strength. His finger and hand abrasions healed without incident (Figure 5). His mother contacted the plastic surgery clinic 6 months after his injury and cancelled his follow-up appointment because he was doing well without any subjective complaints or functional limitation of his forearm. Of note, a few days after the patient's injury, the patient's family caught the flathead catfish in the same location where the injury was sustained and estimated its weight to be about 60 pounds.

\section{Discussion}

Catfish noodling started as a folk tradition in the South, although recently it has become more popular as a sport and recreational activity. ${ }^{1}$ In 2001, a documentary about a catfish noodling championship in Oklahoma, "Okie Noodling," was released. After that, there have been numerous references to noodling in television shows, as well as a television series on Animal Planet dedicated solely to the practice. The goal is to catch the fish with only the fisherman's hands. Noodling is also known as hand fishing, catfisting, grabbling, graveling, hogging, cat-daddling, dogging, gurgling, tickling, and stumping. ${ }^{20}$ Catfish noodling is often performed during the spawning season, early May through late July. During this time fish will search for protective covering, often a hole or rocky crevice, to spawn. Once the eggs are laid, the male fish stays to fan the eggs, which is thought to improve oxygenation. The most targeted catfish family is the bullhead catfish (Ictaluridae), although other species include the flathead catfish (Pylodictis olivaris), blue catfish (Ictalurus furcatus), and channel catfish (Ictalurus punctatus). ${ }^{1}$ Upon discovering a likely spot for a fish, the noodler will extend his hand under the water into the crevice hoping to encounter a catfish. When disturbed, catfish will bite the object disturbing the egg mass. Once the catfish bites on the noodler's hand, the noodler will attempt to bring it to the surface of the water while the catfish attempts to spin as a natural reaction to being trapped. That is when most injuries occur.

Flathead catfish have villiform teeth on their upper and lower jaws. ${ }^{1}$ These can cause abrasion injuries to the noodler when attempting to pull the fish from the water (Figure 1). Catfish also possess spines along their dorsal and pectoral fins that can be extended when threatened, making it difficult to be swallowed or apprehended. In a review of 83 catfish stings in Mississippi, puncture wounds and lacerations of the upper extremities accounted

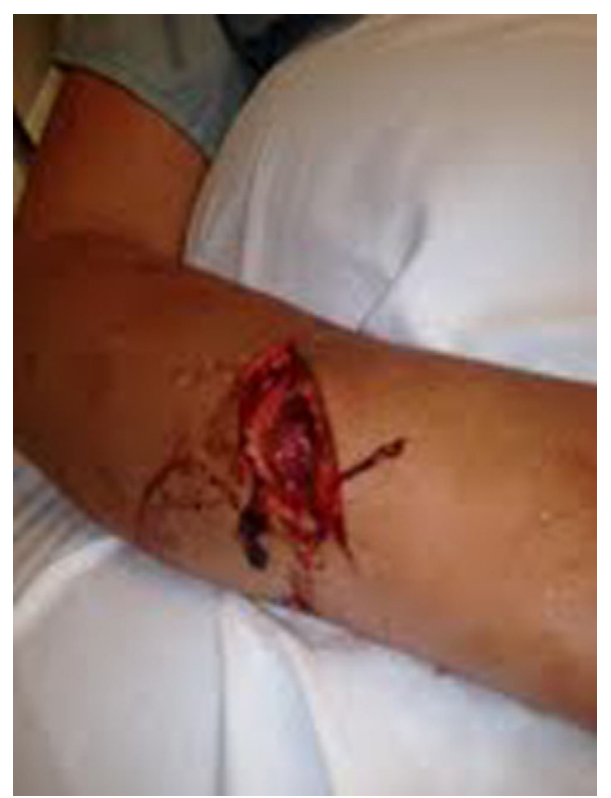

Figure 2. Laceration to patient's middorsal forearm, before debridement. 


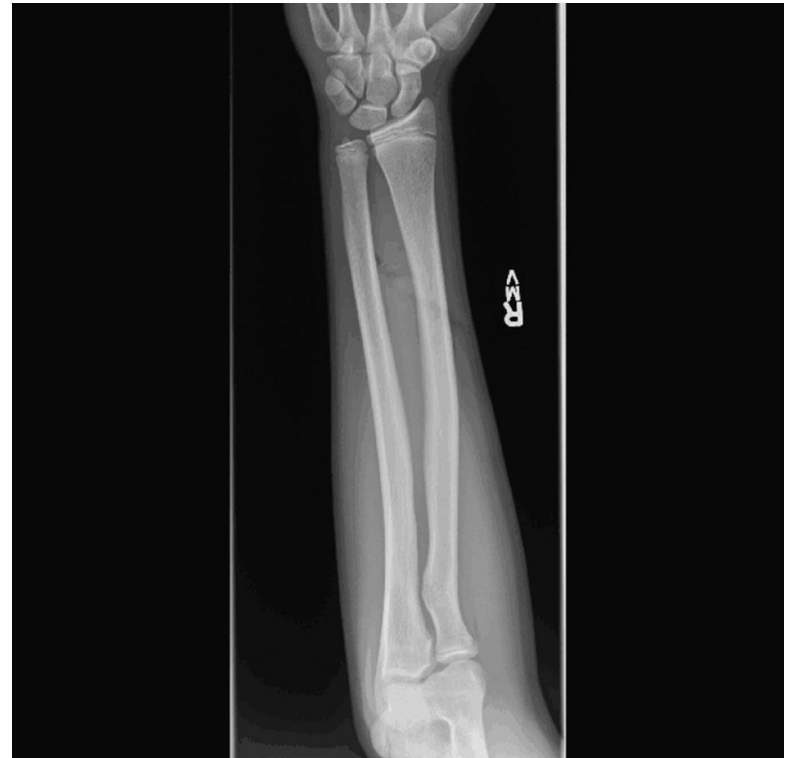

Figure 3. Anterior-posterior radiographs at emergency department presentation demonstrating gas in the extensor surface soft tissues, indicating the location of the laceration and without visible foreign bodies.

for 59 of the 83 cases of the survey (approximately $71 \%$ ). ${ }^{9}$ Puncture wounds and stings from the spines can be severe. A case report described a 12-year-old boy with an ulnar nerve deficit that resulted in the loss of active motion of the fourth and fifth digits. ${ }^{13}$ Puncture wounds can also lead to foreign bodies in the injured noodler's upper extremity that often can be detected by plain film radiographs. ${ }^{21}$ Injuries reported from detached catfish spines include radial artery injuries and severe tissue necrosis of the superficial and deep fascia along the course of the anterior tibial tendon. ${ }^{10,18}$

A number of salt water catfish (Plotosus lineatus) and fresh water catfish (Heteropneustes fossilis) are capable of spine envenomation. ${ }^{22}$ The spines are encased by glandular tissue within an integumentary sheath. Venom is delivered when a spine is damaged or pressed upon, the venom is released and transmitted through the spine into the wound. ${ }^{2,4}$ Catfish venom varies among species and can include hemolytic, dermonecrotic, inflammatory, and vasoconstrictive toxins. ${ }^{6,22-24}$ The venom is known to cause reactions including erythema, edema, local hemorrhage, and tissue necrosis. ${ }^{5,23-25}$ Some catfish, such as the Arabian Gulf catfish (Arius thalassininus) can secrete toxin (crinotoxin) through their epidermal skin cells causing pain, tissue necrosis, and muscle fasciculations. ${ }^{26}$

Aquatic infection can result from a catfish spine or other submerged hazardous structures encountered during noodling. Case reports of infections secondary to catfish injuries include strains of Aeromonas, Vibrio,
Mycobacterium marinum, Proteus vulgaris, Morganella morganii, and Edwardsiella tarda bacteria. ${ }^{7,27,28}$ Often these infections are polymicrobial. ${ }^{15-17,19}$ In the case of $E$ tarda infections, mortality rates have been reported for as many as $44 \%$ of patients, although most are immunocompromised. ${ }^{29} M$ Marinum infections have been known to have an atypical, often delayed presentation, making awareness for aquatic exposure necessary. ${ }^{19,30}$ Systemic complications due to secondary infection from retained catfish spines or other foreign bodies can lead to systemic effects such as cardiac dysrhythmias, hypotension, respiratory distress, and neurological symptoms. ${ }^{15,17}$

\section{RECOMMENDATIONS}

Management of catfish injuries varies depending on the specific injury and its severity. A detailed history of how the injury occurred is important for identifying potential pathogens and to alert the physician to potential complications. A careful physical examination should be performed to evaluate the sites of any puncture wounds, abrasions, lacerations, or locations of possible spine envenomation. This examination should include careful neurovascular evaluation of the injured extremity as well as assessing the injury for local signs of serious inflammatory reaction. Suspected foreign body injury should be evaluated with radiographs. Continued observation for systemic effects is important, and symptoms should be treated.

After evaluation, any puncture wounds, lacerations, and abrasions should be copiously irrigated with normal saline

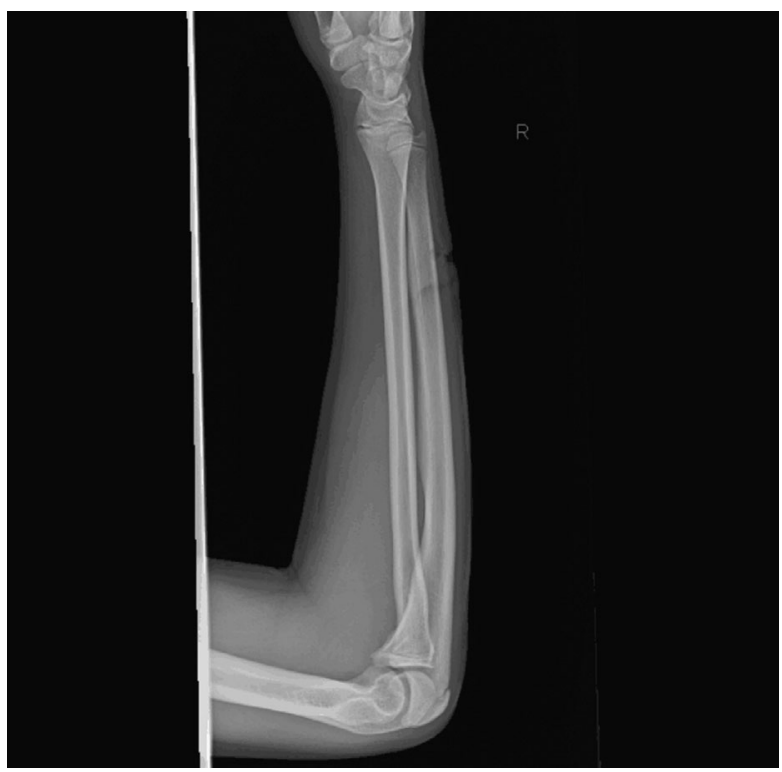

Figure 4. Lateral radiographs at emergency department presentation demonstrating gas in the extensor surface soft tissues, indicating the location of the laceration and without visible foreign bodies. 


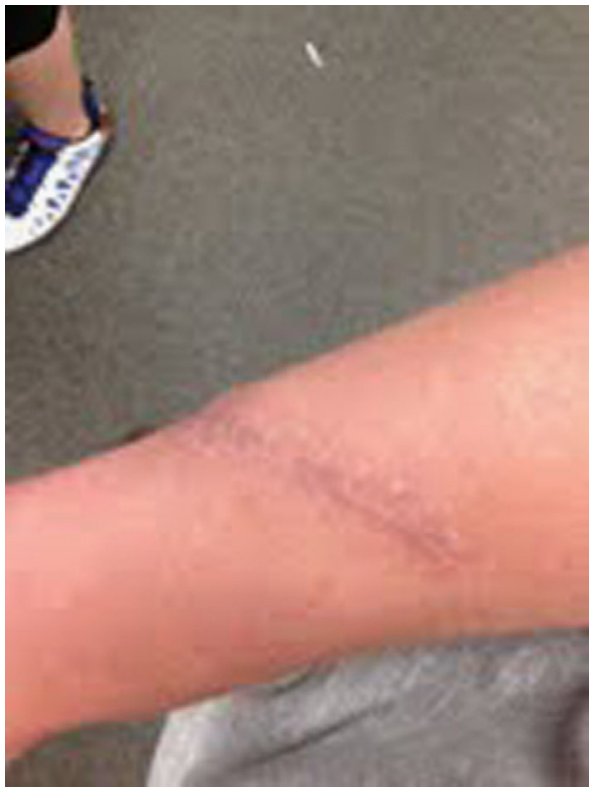

Figure 5. Healed wound 11 months after injury.

and debrided of any necrotic tissue. When a foreign body is present, surgical treatment for removal should occur after antibiotic administration. ${ }^{7,14,17,31,32}$ Myonecrosis can lead to the need for digital amputation or even transhumeral amputation..$^{3,17,27}$ Wounds should be left open to close by secondary intention or undergo delayed primary closure. Tetanus prophylaxis should be given if indicated. $^{22}$ Owing to the prevalence of gram negative rods found in freshwater wounds, empiric antibiotic coverage with both gram positive and gram negative coverage is warranted until final cultures are available. ${ }^{31}$ When envenomation is suspected, immediate treatment is to immerse the injured extremity in hot water $\left(45^{\circ} \mathrm{C}\right)$ for 30 to 90 minutes, as catfish toxins are heatlabile. ${ }^{8,9,11,15,17,22,24}$ Cryotherapy is contraindicated. ${ }^{33}$

As in the case presented here, tendon injuries due to a deep laceration are possible. Our patient sustained significant extensor tendon injuries requiring urgent surgical treatment. As in any contaminated wound, urgent irrigation and debridement is important, as are parenteral antibiotics. Complete extensor tendon injuries can range from purely tendinous more distally in the hand and fingers to injuries involving the musculotendinous junction or proximally only muscle. It is important to repair these injuries expeditiously to restore function to the injured extremity. Specific repair techniques vary according to the location and nature of the specific injury. In the acute setting, that involves direct suture repair of all injured structures. Postoperative immobilization and specific rehabilitation protocols also vary based on quality of repair and injury location. Recently, the trend has been toward earlier protected mobilization to decrease the incidence of stiffness, joint contracture, and adhesions that may limit tendon gliding within their synovial sheaths. ${ }^{34,35}$

In summary, noodling for catfish is becoming a more common recreational activity in the United States. While rare, significant injuries can occur. Potential injuries include lacerations, aquatic infections, catfish spine envenomation, and foreign body reactions. Prompt recognition is important for treatment, which may include antibiotics, wound care, and surgical intervention such as irrigation and debridement, muscle-tendon repair, and even amputation.

\section{References}

1. Salazar DA. Noodling: an American folk fishing technique. J Pop Culture. 2002;35:145-155.

2. Ajmal N, Nanney LB, Wolfort SF. Catfish spine envenomation: a case of delayed presentation. Wilderness Environ Med. 2003;14:101-105.

3. Baack BR, Kucan JO, Zook EG, Russell RC. Hand infections secondary to catfish spines: case reports and literature review. J Trauma. 1991;31:1432-1436.

4. Birkhead WS. The comparative toxicity of stings of the ictalurid catfish genera Ictalurus and Schilbeodes. Compar Biochem Physiol. 1967;22:101-111.

5. Blomkalns AL, Otten EJ. Catfish spine envenomation: a case report and literature review. Wilderness Environ Med. 1999;10:242-246.

6. Burnett JW, Calton GJ, Morgan RJ. Catfish poisoning. Cutis. 1985;35:208.

7. Carty MJ, Kutz RH, Finley RL Jr, Upton J, Rogers GF. Digital catfish envenomation mimicking necrotizing fasciitis. Plastic Reconstruct Surg. 2010;126:226e-230e.

8. Cook L. Prehospital incident profiles. Gone fishin. JEMS. 2002;27:75-78.

9. Das SK, Johnson MB, Cohly HH. Catfish stings in Mississippi. South Med J. 1995;88:809-812.

10. Ferlic RJ, Bonatz E, Robbin ML. Radial artery injury from a catfish sting. Am J Orthop (Belle Mead NJ). 2003;32:412-414.

11. Haddad V Jr, Favero EL Jr, Ribeiro FA, et al. Trauma and envenoming caused by stingrays and other fish in a fishing community in Pontal do Paranapanema, state of Sao Paulo, Brazil: epidemiology, clinical aspects, and therapeutic and preventive measures. Revista da Sociedade Brasileira de Medicina Tropical. 2012;45:238-242.

12. Hargreaves JE, Lucey DR. Life-threatening Edwardsiella tarda soft-tissue infection associated with catfish puncture wound. J Infect Dis. 1990;162:1416-1417.

13. Hess JR, Rocque BG, Mackinnon SE, Hunter DA. Ulnar nerve deficit after catfish sting. South Med J. 2005;98:750-751.

14. Howard RJ, Burgess GH. Surgical hazards posed by marine and freshwater animals in Florida. Am J Surg. 1993; 166:563-567. 
15. Jesus JE, Schrupp Berg H, Tibbles C, Wolfe R. Necrotizing fasciitis in the setting of marine injury. $J$ Emerg Med. 2011;40:539-542.

16. Midani S, Rathore MH. Vibrio species infection of a catfish spine puncture wound. Pediatr Infect Dis J. 1994;13:333-334.

17. Murphey DK, Septimus EJ, Waagner DC. Catfish-related injury and infection: report of two cases and review of the literature. Clin Infect Dis. 1992;14:689-693.

18. Roth BJ, Geller SM. Deep soft-tissue necrosis of the foot and ankle caused by catfish envenomation: a case report. $J$ Am Podiatr Med Assoc. 2010;100:493-496.

19. Thanou-Stavraki A, Sawalha AH, Crowson AN, Harley JB. Noodling and Mycobacterium marinum infection mimicking seronegative rheumatoid arthritis complicated by anti-tumor necrosis factor alpha therapy. Arthritis Care Res. 2011;63:160-164.

20. Wikipedia, 2013. Noodling. Available at: http://en.wikipe dia.org/wiki/noodling.

21. Hoffman J. Extremely late presentation of catfish spine injury to the hand. Wilderness Environ Med. 2010;21:383.

22. Dorooshi G. Catfish stings: a report of two cases. $J$ Res Med Sci. 2012;17:578-581.

23. Calton GJ, Burnett JW. Catfish (Ictalurus catus) fin venom. Toxicon. 1975;13:399-403.

24. Satora L, Kuciel M, Gawlikowski T. Catfish stings and the venom apparatus of the African catfish Clarias gariepinus (Burchell, 1822), and stinging catfish Heteropneustes fossilis (Bloch, 1794). Ann Agric Environ Med. 2008;15: 163-166.
25. de Haro L, Pommier P. Envenomation: a real risk of keeping exotic house pets. Vet Hum Toxicol. 2003;45:214-216.

26. Frederette SR, Derk FF, Nardozza AJ. Catfish spine injury of the foot. J Am Podiatr Med Assoc. 1997;87:187.

27. Crosby SN, Snoddy MC, Atkinson CT, Lee DH, Weikert DR. Upper extremity myonecrosis caused by Edwardsiella tarda resulting in transhumeral amputation: case report. $J$ Hand Surg. 2013;38:129-132.

28. Huang G, Goldstein R, Mildvan D. Catfish spine envenomation and bacterial abscess with Proteus and Morganella: a case report. J Med Case Rep. 2013;7:122.

29. Wilson JP, Waterer RR, Wofford JD Jr., Chapman SW. Serious infections with Edwardsiella tarda. A case report and review of the literature. Arch Intern Med. 1989;149:208210.

30. Noonburg GE. Management of extremity trauma and related infections occurring in the aquatic environment. $J$ Am Acad Orthop Surg. 2005;13:243-253.

31. Beckert BW, Puckett CL, Concannon MJ. Analysis of freshwater pathogens: a guide to rational empiric antibiotic coverage. Missouri Med. 2004;101:219-221.

32. Elko L, Rosenbach K, Sinnott J. Cutaneous manifestations of waterborne infections. Curr Infect Dis Rep. 2003;5:398406.

33. Pacy H. Catfish and stingrays: hot water is first aid. Aust Fam Physician. 1998;27:343-344.

34. Armstrong $\mathrm{MB}$, Adeogun $\mathrm{O}$. Tendon injuries in the pediatric hand. J Craniofac Surg. 2009;20:1005-1010.

35. Matzon JL, Bozentka DJ. Extensor tendon injuries. J Hand Surg. 2010;35:854-861. 